\title{
O PAPEL SOCIAL DOS MUSEUS E A MEDIAÇÃO CULTURAL: CONCEITOS DE VYGOTSKY NA ARTE-EDUCAÇÃO NÃO FORMAL
}

\author{
Júlia Rocha Pinto \\ Universidade Estadual Paulista UNESP
}

\section{Resumo:}

Este artigo faz uma reflexão sobre as práticas educativas realizadas em Museus e espaços promotores da Arte. O texto trabalhará a estrutura museal no geral, trazendo alguns aspectos históricos desta instituição. Coloca-se a possibilidade de papel social que o museu pode desempenhar, refletindo a razão das pessoas frequentarem estes espaços e percebendo a estrutura de trabalho que predispõe os museus. A partir de uma compreensão do caráter social e educativo destas instituições é que se traz a contribuição de Lev S. Vygotsky para a prática da educação em museus de arte. Compreendida como mediação cultural, a educação em exposições propõe que haja uma relação dialogal entre o mediador, a obra e o público.

Palavras-chave: ensino de arte, mediação cultural, museu.

\begin{abstract}
:
This article is a reflection on educational practices held in museums and art spaces. The text will work with the museum structure in general, bringing some historical aspects of this institution. This raises the possibility of social role that the museum can play, reflecting the reason people attend these spaces and realizing the framework that predisposes museums. From an understanding of the social and educational characteristic of these institutions is what brings the contribution of Lev S. Vygotsky to the practice of education in art museums. Understood as cultural mediation, the education in exhibitions suggests for there to be a dialogue relationship between the mediator, the work and the public.
\end{abstract}

Key-words: arts education, cultural mediation, museum.

"Os museus são espaços que suscitam sonhos".

Walter Benjamin

Os museus são espaços provocadores de sonhos, como romantizou Benjamin, eles são ambientes de devaneios e fantasias. Entrar em um espaço expositivo pode inserir o sujeito em outro mundo, abrindo possibilidades e desconstruindo paradigmas. Essa 
possibilidade nada mais é do que a gama de transformações que pode provocar a imagem, configurando aqui o discurso em Artes Visuais.

Da modernidade ao mundo contemporâneo, os museus são reconhecidos por seu poder de produzir metamorfoses de significados e funções, por sua aptidão para a adaptação aos condicionamentos históricos e sociais e por sua vocação para a mediação cultural. Eles resultam de gestos criadores que unem o simbólico e o material, que unem o sensível e o inteligível. Por isso mesmo, cabe-lhes bem a metáfora da ponte lançada entre tempos, espaços, indivíduos, grupos sociais e culturas diferentes; ponte que se constrói com imagens e que tem no imaginário um lugar de destaque. (CHAGAS; NASCIMENTO, 2008a, p. 59)

Esta afirmação de Mário de Souza Chagas e José do Nascimento Junior funciona como propedêutica deste artigo, onde se propõe pensar o papel social e educativo que os museus desempenham. A visita a um museu abre a possibilidade de ressignificar o olhar para as coisas que nos cercam, na mesma medida que nos desloca para outra cultura, outro tempo. Os museus são espaços de encontros. Encontro com o outro, com o objeto, com a minha própria cultura.

Ainda que espaços de encontros, os museus também são desencadeadores de ausências. De certa maneira, os museus nos angustiam e, mesmo assim, abrigam o relicário de nossa humanidade e memórias que nos registram. É preciso abandonar a ingenuidade para entrar em contato com estes objetos, é necessário que haja uma apropriação deles. Deve-se aceitar os museus como campos de tensão. "Tensão cíclica, entre mudança e permanência, entre o perene e o volátil, entre a diferença e a identidade, entre o passado e o futuro, entre a memória e o esquecimento, entre o poder e a resistência" (CHAGAS; NASCIMENTO, 2008a, p. 65).

Os museus de arte situam-se também dentro destes conceitos de deslocamento e tensão. Dentro de uma perspectiva histórica, as artes visuais tal qual conhecemos hoje têm uma marcação temporal; visto que somente a partir do Renascimento é que surge a postura e, sobretudo, a nomenclatura do artista como tal. Antes disso, toda manifestação artística era proveniente ou destinada a um culto, costume ou crença. É somente no Renascimento que arte e artesanato se distinguem, quando a arte se torna mais mental e separada do mecanismo da prática por si, como afirma Cocchiarale (2006).

Assim como a prática artística sempre foi realizada, ainda que não com esta terminologia, o ato de colecionar sempre esteve presente nas ações humanas; desde a Pré- 
História ${ }^{1}$ quando o homem reunia objetos, organizando-os de forma sistematizada. Geoffrey Lewis (2004, p. 1) registra que "(...) o papel do museu é preservar a propriedade cultural mundial e interpretá-la ao público; esta preservação provém da prática do colecionismo". Ele informa, ainda, que "As coleções de objetos foram reunidas devido às suas associações pessoais ou coletivas ocorridas na antiguidade" (2004, p. 2).

A prática do colecionismo provinha, sobretudo, de pessoas abastadas que recolhiam objetos exóticos, pinturas, esculturas, recordações de viagens e documentos através de critérios pessoais e os exibiam em suas casas, eram conhecidos como gabinetes de curiosidades.

A partir do momento que essa coleção precisou ser reservada, alocada em algum espaço específico é que se compreende a criação de um museu. "O desenvolvimento da ideia de museu ocorre no princípio do segundo milênio a.C. em Larsa, na Mesopotâmia, onde cópias de antigas inscrições foram reproduzidas para uso educativo nas escolas daquele tempo" (LEWIS, 2004, p. 1).

Percebe-se que é própria do homem a necessidade de perpetuar o conhecimento construído e adquirido; e é fundamental preservar sua memória e registrar sua história. retorno ao passado é realizado através da guarda dos registros, relatos e documentações. Este acesso pode ser realizado mediante os museus; não que estes sejam a obrigatoriedade do antigo, mas um meio de mediação com o passado assim como com o futuro. Não se pode negar a ligação que o museu tem com o registro, da memória, como bem explicitam Chagas; Nascimento (2008a, p. 66):

\begin{abstract}
Talvez fosse adequado, para melhor compreendê-los numa perspectiva crítica, aceitar a obviedade: os museus são lugares de memória e de esquecimento, assim como são lugares de poder, de combate, de conflito, de litígio, de silêncio e de resistência; em certos casos, podem até mesmo ser não-lugares. Toda a tentativa de reduzir os museus a um único aspecto corre o risco de não dar conta da complexidade do panorama museal no mundo contemporâneo.
\end{abstract}

Não acontecendo esta redução a uma única visão dos museus é que se pode compreender a relevância desta instituição na pós-modernidade. Em vista da necessidade

\footnotetext{
${ }^{1} \mathrm{O}$ indivíduo social na Pré-História colecionava através das imagens gravadas nas paredes. A figuração imagética de um animal representava a possibilidade ou a realidade que aquele sujeito teria de possuí-la.
} 
de dar conta da estrutura contemporânea é que se pesquisa o que foram os museus no passado.

Portanto, o museu - etimologicamente da palavra mouseion, a casa das musas sempre existiu como prática ainda que não nominalmente desta forma. Quando os mais favorecidos financeiramente adquiriam bens de consumo para a indução do poder absoluto e passaram a explorar deste recurso imagético para colocá-los como superiores às classes menos favorecidas, já se constituía a concepção do que hoje conhecemos como museu. Conforme Chagas; Nascimento (2008a, p. 59),

Durante longo tempo, os museus serviram para preservar os registros da memória das classes mais abastadas, serviram como dispositivos ideológicos do Estado e também para disciplinar e controlar o passado, o presente e o futuro das sociedades em movimento.

O caráter social modificou drasticamente a posição destes espaços/templos, visto que a acessibilidade é crescente e processual, “(...) o museu está passando por um processo de democratização, de ressignificação e de apropriação cultural" (CHAGAS; NASCIMENTO, 2008a, p. 59-60). Porém, é necessário enfatizar que nem sempre as coleções estiveram ao acesso de todos.

Ainda que tenha surgido do colecionismo, impreterivelmente deve-se reconhecer a existência de museus na contemporaneidade que não lidam com a constituição de acervo que precede uma instituição museal. Muito mais do que um espaço de reserva de acervo, hoje os museus são espaços de escolhas, pesquisa e intencionalidades conforme definição oferecida pelo Comitê Internacional de Museus - ICOM (2009, s/p):

Um museu é uma instituição permanente, sem fins lucrativos, a serviço da sociedade e de seu desenvolvimento, aberto ao público, que adquire, conserva, pesquisa, divulga e expõe, para fins de estudo, educação e lazer, testemunhos materiais e imateriais dos povos e seu ambiente.

A partir dessa conceitualização formal oferecida por um órgão centralizador da gestão dos museus em âmbito nacional e internacional pode-se também determinar a relação entre museu e outros espaços culturais. Por exemplo, as galerias que comercializam as obras de arte como produtos de mercado, adquirindo-as e revendendo-as não se enquadram nessa concepção de museu. Porém, todo e qualquer espaço cultural, seja ele público ou privado, que se proponha a expor as obras para fins de ensino, conhecimento, etc. pode ser chamado de museu. 
Retornando ao processo histórico, desde a Grécia Antiga os templos eram locais destinados às artes e à ciência e por isso são considerados como equivalentes aos museus. No século XVII, conforme Castellen (2004), as coleções particulares de nobres europeus passaram a ser visitadas, quando foi permitido o acesso aos palácios e outros locais onde eram guardados objetos de valor. A visitação inicialmente era restrita a pesquisadores e estudantes de artes, porém aos poucos tomou novos campos e tornou-se acessível a todos.

Com a Revolução Francesa, em 1789, foi que o acesso às grandes coleções efetivou-se. Neste período, as principais tarefas dos museus restringiam-se a coletar e conservar, somente. Quando as visitas tornaram-se constantes e as exposições práticas corriqueiras, os museus passaram por mudança de coordenação para facilitarem o acesso aos seus acervos.

No Brasil, a mais antiga experiência museológica de que se tem notícia remonta ao século XVII e foi desenvolvida durante o período da dominação holandesa em Pernambuco. "Consistiu na implantação de um museu (incluindo jardim botânico, jardim zoológico e observatório astronômico) no grande Palácio de Vrijburg" (CHAGAS; NASCIMENTO, 2008b, p. 35). Posteriormente, já no século XVIII, surgiu no Rio de Janeiro a Casa de Xavier dos Pássaros - um museu de história natural - que existiu até o início do século XIX. Ainda que estas duas instituições não tenham perpetuado, elas são indícios de que os museus, através de ações preservacionistas, foram pensados no país durante a época colonial.

A concretização de uma estrutura museal no Brasil aconteceu com a vinda da família real, que em 1818 criou o Museu Real, hoje Museu Nacional da Quinta da Boa Vista. Com este exemplo caracteriza-se a afirmação que durante muito tempo o ato expositivo e colecionador esteve abarcado pelos nobres e pela classe mais abastada financeiramente. Como museu de artes, propriamente dito - visto que o Museu Real tinha em seu acervo objetos pessoais de todo o tipo da família real - temos em 1826, a execução do primeiro salão da Academia Imperial de Belas Artes, que deu origem ao Museu Nacional de Belas Artes.

De forma gradual, a constituição de um sistema museal no Brasil foi se estabelecendo efetivamente no século XIX. Em vista disso, compreende-se que "antes mesmo do surgimento das universidades e de institutos públicos de preservação do patrimônio cultural, os museus já exerciam as funções de pesquisa, preservação, comunicação patrimonial, formação e capacitação profissional" (CHAGAS; NASCIMENTO, 2008b, p. 36). 
Todavia, foi somente entre os anos 1940 e 1950, já no século XX, que a museologia se consolidou no Brasil; com a publicação de livros e a criação de diversos museus. Neste período aconteceram importantes eventos que firmaram este novo campo, como o $1^{\circ}$ Congresso Nacional de Museus, em Ouro Preto (MG) no ano de 1956 e o Seminário Regional da UNESCO sobre a Função Educativa dos Museus, em 1958, no Museu de Arte Moderna do Rio de Janeiro (RJ).

Diversos outros órgãos foram criados, outras parcerias estabelecidas e nos anos 70 e 80 o panorama museológico brasileiro estava em efervescência, compondo-se de novas ideias, encontros, debates e propostas de uma nova museologia, mais ativa e participativa. Nesse contexto histórico é que surge, em 1986, o Sistema Nacional de Museus, com o objetivo de articular e apoiar financeiramente projetos museológicos.

As novas concepções que foram trazidas para a museologia aproximaram mais ainda esta da questão do patrimônio. Este caminho que o estudo dos museus trilhou no Brasil constitui uma forte relação entre as áreas de preservação de patrimônio cultural e ações de comunicação, conforme Chagas; Nascimento (2008b, p. 40):

\begin{abstract}
As relações entre os museus e o patrimônio não nasceram e não se esgotaram no século XX. Esse entendimento favorece a compreensão de que as categorias museu e patrimônio podem ser consideradas como campos complementares e, por isso mesmo, uma não se reduz obrigatoriamente à outra.
\end{abstract}

Em suma, os museus não são apêndices do campo patrimonial; eles constituem práticas sociais específicas com trajetórias próprias. Evidentemente que os museus estão inseridos no campo do patrimônio, mas ainda assim é preciso marcar que estes têm dilatado os limites do campo, expandindo fontes de estudo e pesquisa. A musealização como prática social específica derramou-se para fora dos museus institucionalizados, e os museus tornaram-se campos de atuação e comunicação social.

\title{
O papel social dos museus
}

O museu "(...) tem um papel cultural importante, além de abrigar os registros do tempo, é um veículo a serviço do conhecimento e da informação que contribui para o desenvolvimento da sociedade", conforme Almandrade (2007, s/p). O trabalho do museu é um serviço para a coletividade, e por isso exige padrões mais elevados de prática profissional. Tanto na abordagem com o público, como no relacionamento interpessoal entre os funcionário e gestores do museu é impreterível reconhecer que há um código de ética 
profissional. O código de ética nem sempre está implantado na concepção inicial do espaço museológico, mas é conferido por instituições como o ICOM, ou o IBRAM - Instituto Brasileiro de Museus.

Para prestar serviço à sociedade, o museu deve disponibilizar seu acervo para o público com períodos razoáveis, reapresentando sua coleção e sempre buscando nova significação em cada exposição. Sendo assim, o público comparece regularmente no espaço, buscando compreender cada novo conjunto de obras como uma unidade de visão de um curador. Além disso, por ter caráter social e ser de função educacional, é dever do espaço receber seu público "com normas apropriadas para assegurar a saúde, segurança e acessibilidade aos seus visitantes e pessoal. Deverá existir considerações especiais na acessibilidade de pessoas com necessidades específicas" (Lewis, 2004, p. 6). Somente assim, o museu atende seu papel de prestar serviço ao ensino de seus espectadores, reafirmando-se como instituição cultural e educacional.

Atualmente muitos museus têm abordado esta questão da acessibilidade em seu trabalho. Sendo assim, materiais são adaptados para o recebimento de grupos que não têm o hábito de estar dentro da instituição. A inclusão destes é mais uma política de formação de público que os museus têm empenhado grande trabalho; visto que no Brasil, conforme dados do IBGE, 92\% dos brasileiros nunca foram a um museu e 93,4\% dos brasileiros jamais frequentaram uma exposição de arte.

Outra vertente da inclusão que também tem sido reavaliada contemporaneamente é a questão multicultural. Durante muito tempo o sistema de arte manteve-se focado apenas na esfera branca, européia e norte-americana. "A grande acusação é que os museus refletem apenas a cultura de uma única classe social, de classe dominante, a cultura de código alto" (BARBOSA, 1998, p. 98). Hoje, porém, com a valorização das artes afrodescendentes ocasionada, sobretudo pelo trabalho de museus voltados estritamente para esta questão, a postura está sendo modificada e o negro passa a ser figura mais presente neste campo restrito.

O que ocorreu durante muitos anos foi que parte do público que possivelmente freqüentaria os museus, continuou na inércia ausente da instituição por não reconhecer sua identidade dentro daquilo que era exposto nestes espaços. A partir do momento que há esta valorização de novas linhas de produção artística e estas são incorporadas as curadorias, este público antes "excluído" passa a mais frequentemente visitar os museus e estar em contato com a arte. 
Em relação estritamente aos museus de artes visuais a especificidade torna-se enriquecedora aos aspectos museológicos. Estar em contato com a arte dentro de um espaço apropriado apresenta-se como experiência sensível e estética, tal qual fala Hernández (1998, p. 83):

Por esta razón, cada objeto, dentro del museo, adquiere una dimensión simbólica que ha de ser interpretada según las líneas directrices de la hermenéutica cultural. Toda obra de arte puede ser considerada como un objeto cultural que participa activamente de la dinámica del momento histórico en el que ha sido creada. Esto significa que la obra expuesta en el museo participa de una continuidad histórica y cultural, que viene determinada por el tiempo y el espacio. $\mathrm{Y}$, al mismo tiempo, se presenta como un objeto que es capaz de abrir el espíritu de quien lo contempla a una experiencia mística y estética que le sobrepasa, más allá de sus propios límites. Y el museo sigue siendo el espacio más apropiado para la realización de cualquier experiencia estética.

Ampliando ainda a questão, concebe-se os museus como mais do que espaços de experiências estéticas, mas também como ambientes de prática e fomento cultural. Segundo Thistlewood (1999, p. 153)

é importante compreender o enorme potencial dos museus de arte como condensadores culturais. Várias influências de todo o mundo têm sido sintetizadas neles, a ponto de os museus de arte de hoje (...] serem um mistura de palácio, monumento popular, academia, laboratório propriedade pública e casa da moeda. Nesse sentido não é uma instituição que os estudantes (ou qualquer outro cidadão) sejam displicentemente introduzidos, porque será impossível ignorar seu conteúdo cultural. A introdução ao museu de arte e o seu acervo deve ser orientada, isto é, acompanhada de instrução.

Concebe-se, portanto, a prática do museu como um espaço de promoção (além de ser de produção) cultural. Para a realização desta experiência estética referida é necessário antes que se perpetue uma política de trazer o público ao museu. O que faz com que o espectador se dirija ao espaço expositivo? O que este espectador busca ao adentrar neste campo? Qual é o perfil do público que realmente frequenta os museus?

No livro "O amor pela arte" Pierre Bourdieu e Alain Darbel realizaram uma pesquisa para perceber a motivação que leva as pessoas a frequentarem museus de arte. Bourdieu (2007) afirma que os museus abrigam objetos preciosos artísticos que se encontram, paradoxalmente, acessíveis a todos, porém interditados à maioria das pessoas. Em meados 
dos anos 60, os dois pesquisadores realizaram o trabalho de pesquisa comparativa, em museus de cinco países da Europa: Espanha, França, Grécia, Holanda e Polônia, procurando os fatores que pudessem favorecer ou dificultar a prática da visita a museus.

A pesquisa teórica realizada por Bourdieu - a partir de dados obtidos por Darbel apresenta a excelência de colocar em evidência as condições necessárias para que se possa realizar a apreensão da obra de arte. Sendo que essa apreensão depende em sua intensidade, modalidade e própria existência do controle que o espectador detém do código genérico e específico da obra. Depende, para isso, da comunicação pedagógica, da cultura recebida no meio familiar e da aprendizagem recebida na escola.

A primeira constatação apresentada pelo teórico é obtida através da análise de questionários realizados com os visitantes dos museus selecionados para a pesquisa é que "A estatística revela que o acesso às obras culturais é privilégio da classe culta; no entanto, tal privilégio exibe a aparência da legitimidade" (2007, p. 69). A classe culta é, portanto, mais inserida dentro do campo e articula mais os pensamentos produzidos naquele contexto.

Uma questão que sobrepuja a formação culta é a demanda econômica que detém este público em potencial. Fica claro durante a pesquisa realizada por Bourdieu que se considera mais inserido naquele espaço o visitante que tem mais poder econômico, ainda que a instituição seja de caráter público. O sociólogo coloca que mais do que disfunção econômica, o visitante percebe a dissonância na precisão cultural (2007, p. 69):

Considerando que nada é mais acessível do que os museus e que os obstáculos econômicos - cuja ação é evidente em outras áreas - têm pouca importância, parece que há motivos para invocar a desigualdade natural das "necessidades culturais".

Essa necessidade cultural valoriza a questão central deste trabalho, visto que esta pode ser sanada com as ações educativas realizadas nestes espaços expositivos. Compreende-se que essa lacuna provocada pela falta de instrução e colocada por Bourdieu como necessidade cultural é a evidência da falta do habitus culto e que não permite o leigo reconhecer o valor daquele objeto colocado naquele contexto específico. Conforme o autor da pesquisa (2007, p. 71) "A obra de arte considerada enquanto bem simbólico não existe como tal a não ser para quem detenha os meios de apropriar-se dela, ou seja, de decifrá-la".

Assim, só entende o valor simbólico agregado ao objeto artístico quem se sente familiarizado com aquele bem cultural. O ser humano é perceptivelmente avesso a se colocar diante daquilo que desconhece e é por isso que só frequenta museus e espaços 
culturais e expositivos aquele que se aproxima da temática. Só aquele que arrisca conhecer um novo campo dedicará a ele tempo o suficiente para que aconteça uma compreensão deste.

O tempo dedicado pelo visitante à contemplação das obras apresentadas, ou seja, o tempo de que tem necessidade para 'esgotar' as significações que the são propostas, constitui, sem dúvida, um bom indicador de sua aptidão em decifrar e saborear tais significações: a inexauribilidade da 'mensagem' faz com que a riqueza da 'recepção' (avaliada, grosseiramente, por sua duração) dependa, antes de tudo, da competência do 'receptor', ou seja, do grau de seu controle relativamente ao código da 'mensagem'. (BOURDIEU, 2007, p. 71)

Desta forma, o tempo de interlocução entre público e obra depende da capacidade receptora que esse espectador terá para com a obra de arte. O tempo é dimensionado pela amplitude do repertório de interpretações que ele pode dar aquele objeto. O perfil traçado por Bourdieu como sendo do público habitualmente frequentador de museus é, portanto, da classe culta, com alto poder econômico e que é detentora de tempo e necessidade voltados para a cultura.

Conforme Thistlewood (1999, p. 147) "Existem essencialmente dois caminhos para encorajar a frequência aos museus de arte, mas qualquer que seja a escolha é inevitável a responsabilidade educacional". As duas possibilidades apresentadas pelo teórico são de cunho comunicacional do museu: ou este deve atrair o público para dentro de seu campo de atuação, ou deve promover mostras em locais públicos - ambos os caminhos direcionados pela educação.

O tempo que este espectador permanece no espaço com certeza também advém da receptividade deste museu para com o público. A estrutura museológica é composta por diversos núcleos e setores e a harmonia de trabalho entre esses compilará o público ou não dentro do seu espaço. A função educativa do museu é desempenhada por destes núcleos. O programa educativo é quem tem a responsabilidade de receber e formar o público visitante do museu.

\section{A educação no campo artístico}

Nos tempos contemporâneos, onde houve um redimensionamento dos limites poéticos e parece que tudo pode ser objeto artístico, fica cada vez mais difícil a Arte não ser colocada como área de conhecimento para poucos iniciados. Ao público leigo que entra em prévio contato com a arte, geralmente através de exposições, parece estranho deparar-se 
com um readymade ${ }^{2}$ de um objeto cotidiano sendo categorizado como obra a partir do seu deslocamento. Da mesma forma, causa estranhamento chegar a um museu ou espaço cultural e ser impassível diante de um vídeo onde o artista se mutila, colocando sua vida em risco.

Ao tornar-se limitada a uma elite detentora de conhecimento, proprietária do habitus e participante do campo a arte promove-se cada vez mais complexa e de difícil compreensão para o público em geral, conforme Bourdieu (1989, p. 285-6):

A experiência da obra de arte como imediatamente dotada de sentido e de valor é um efeito da concordância entre as duas faces da mesma instituição histórica, o habitus culto e o campo artístico que se fundem mutuamente: dado que a obra de arte só existe enquanto tal, quer dizer, enquanto objeto simbólico dotado de sentido e de valor, se for apreendida por espectadores dotados de atitude e da competência estéticas tacitamente exigidas, podese dizer que é o olhar do esteta que constitui a obra de arte como tal, mas com a condição de ter de imediato presente no espírito que só pode fazê-lo na medida em que é ele próprio o produto de uma longa convivência com a obra de arte.

Ainda que se compreendesse que para tomar a obra de arte com o efeito e o sentido necessários é preciso estar inserido no campo e ser portador do habitus culto é preciso admitir que o campo artístico, no todo, passou por diversas mudanças na pós-modernidade, este é um fato inegável, assim como continua em constantes modificações poéticas, teóricas, imagéticas e conceituais.

Que a Arte não é constante, permanecendo sempre em transformação, ainda que latente, disso há muito se sabe; o que se torna novo é a relação desta com o público. Fernando Cocchiarale (2007) justifica o estranhamento com a arte do pós-modernismo afirmando que a incompreensão é temporalmente crescente: entendemos melhor a arte moderna que a contemporânea, assim como a arte anterior ao modernismo nos parece mais coerente e é melhor compreendida que a arte moderna.

Em vista disso, torna-se, a cada nova produção, mais difícil para os ambientes expositivos adaptarem-se à suas especificidades. Os próprios espaços da arte passaram por modificações e agora é muito mais o campo que delimita a potencialidade do objeto

\footnotetext{
${ }^{2}$ Conceito de apropriação de objetos colocados dentro de espaço expositivo, re-significando o objeto e colocando-o como obra de arte. Criação de Marcel Duchamp, em 1917, ao enviar um urinol (A Fonte) para um Salão de Artes em Paris.
} 
artístico. Segundo Brian O'Doherty (2002, p. 102) "O cubo branco tornou-se arte potencial; seu espaço fechado, um meio alquímico. Arte passou a ser o que era colocado lá dentro, retirado e reposto regularmente". Por ventura dessa autonomia do campo configura-se um descaso com o conceito de obra de arte, visto que o público leigo baseia-se na concepção de que o objeto artístico só o é por conta da especificidade do espaço.

Do cubo branco e suas seis faces neutras inicialmente instauradas para denominar o que é arte, hoje se sabe que é muito menos imparcial do que se imaginava:

A aparente neutralidade da parede branca é uma ilusão. Ela representa uma comunidade com ideias e suposições comuns. (...) A parede imaculada da galeria, embora um produto evolutivo delicado de natureza bastante específica, é impura. Ela subsume comércio e estética, artista e público, ética e oportunismo. (O’DOHERTY, 2002, p. 89-90)

Desvenda-se assim o mito de que a parede branca não oferece interferências para a obra. Pelo contrário, o espaço categoriza a obra de arte como tal, como foi anteriormente citado, instaurando um status de objeto de arte aceito e estigmatizado pelo contexto histórico-artístico. Para o público leigo, que ainda oferece certa resistência a arte no geral é certo que muitos objetos colocados dentro de espaços expositivos só ganham notabilidade por estarem inseridos no campo pré-concebido como artístico.

O público obsoleto também toma esta posição de aceitação passível imposta pela inserção espacial do objeto, há também a vertente do público iniciado que categoriza o espaço expositivo como o degrau para a veneração. Ou seja, dentro deste espaço configura-se uma idolatria nem sempre justificada; no interior deste cubo branco há uma dimensão de sagrado maior do que se pode imaginar. Na introdução do livro de O'Doherty, Thomas McEvilley (2002, p. XIX) revela que "nas galerias modernistas típicas, como nas igrejas, não se fala no tom normal de voz; não se ri, não se come, não se bebe; não se enlouquece, não se canta, não se dança, não se faz amor".

As coibições impostas ao espectador foram durante muito tempo - e ainda o são pretexto para afastar aquele público não tão inserido e disposto ao mercado e ao espaço artístico. Contrapondo essa impossibilidade de interferência no ambiente expositivo surgem os núcleos de arte-educação responsáveis pelo recebimento do espectador nas instituições. Assim, o espaço onde tudo parece ser impedido, interdito, dá lugar a um ambiente de diálogo, trocas, reflexão e experimentação. É notório que essa mudança advém também da postura da Arte, dos artistas, curadores e críticos de arte; se o espaço artístico se modificou, foi porque os sujeitos deste ambiente modificaram suas ações. Todavia atualmente 
compreende-se a arte-educação como a contraposição concreta daquela postura instaurada nas galerias modernistas.

A transição do modernismo para o pós-modernismo é um provável desafio para os professores de arte no geral, visto que a arte valoriza aspectos diferenciados nestas temporalidades. Arthur D. Efland (2005) diz que a educação em arte presente nos dias de hoje valoriza a habilidade de se interpretar a obra de arte mediante o contexto cultural e social. Diferentemente do modernismo, como afirma Efland (2005, p. 177):

\begin{abstract}
A arte-educação baseada sobre uma definição modernista da arte tende a aplicar padrões de bom gosto e critérios de excelência artística, porém tal arte torna-se isolada do resto da experiência, da mesma forma como, de muitas maneiras, os objetos, nos museus, estão isolados da vida. Tal arteeducação haverá de prover uma experiência e apreciação estética para coisas refinadas, mas ela não enfatizará o entendimento cultural e tampouco a base para uma ação social.
\end{abstract}

A arte-educação provida de uma definição pós-modernista está muito mais relacionada e conectada ao contexto de quem vivencia esta experiência - tal qual a obra de arte se desdobra em múltiplos olhares para o espectador.

Diante dos argumentos e desdobramentos postos pela arte contemporânea a importância de ações educativas é fortalecida dentro dos espaços artístico-culturais. O’Doherty (2002, p. 57) diz que "A maior parte da nossa vivência só se torna perfeitamente clara pela mediação", reforçando o valor da presença de um educador qualificado dialogando com espaço(s) e espectador(es).

Cocchiarale (2006) também fala da necessidade de se mediar: "Uma das práticas mais generalizadas do mundo institucional das artes, compreendendo aí o chamado grande público, é a necessidade de mediação pela palavra, para a produção de sentido". É através desta produção de sentido que se pode promover a participação, a reflexão crítica e a transformação da realidade social da arte; afinal os museus e as galerias são espaços de escolhas e intencionalidades - do artista e, sobretudo do público - e por meio destas estratégias é que se pode instigar o espectador.

Assim, enfatiza-se a importância de estar presente alguém qualificado para promover a reflexão pensada para a mostra. O mediador, sobretudo em exposições contemporâneas, toma postura de peça fundamental para que as concepções primordiais da curadoria e do(s) artista(s) sejam atingidas. Rejane Coutinho - citada por Martins (2005, p. 52) - ainda reitera a importância do mediador, colocando que seu papel "é imprescindível para introduzir o 
observador nas questões abordadas pela obra, indicando brechas de acesso no universo tratado pelo artista".

Procurando ainda desvelar o papel da mediação busca-se o porquê da importância de uma interlocução numa exposição. Franz (2001, p. 53) afirma que

O papel do guia, seja ele um profissional do museu ou um professor de classe, é o de mediar a observação de forma que ela seja aproveitada ao máximo. Diante de obras de arte, mais do que dar respostas, ele deve ensinar a fazer boas perguntas, a problematizar, ele deve levar o aluno a mobilizar seu próprio potencial em torno da obra apresentada.

Sendo assim, os agentes mediadores têm o papel de se colocar entre essas referências/expectativas, o professor, o público e a obra, relacionando, dialogando e propondo um contato diferenciado com a arte.

É preciso frisar que assim como em sala de aula o planejamento de uma mediação é dinâmico e permite necessárias mudanças para a efetiva prática educacional. Dentro do espaço museológico, o mediador - ainda que orientado pela proposta da exposição e pela formação geral do núcleo de arte-educação - fará sempre transformações e apropriações das propostas ao receptor. Essa possibilidade de mudança é também colocada para a questão do espaço do museu, conforme Santos (2001, p. 11) apud Castellen (2004, p. 29):

Assim como na educação, o processo museológico é compreendido como ação que se transforma, que é resultado da ação e da reflexão dos sujeitos sociais, em determinado contexto, passível de ser repensado, modificado e adaptado em interação, contribuindo para a construção e reconstrução do mundo.

A compreensão dessa atividade em constante estado de modificação foi também o que fez a associação entre a palavra mediação e a prática de ação educativa realizada em espaços museológicos. Antes da utilização deste termo já havia a prática da educação em museus, é importante salientar; mas a transformação do título demarcou uma modificação também na conduta do educador não-formal.

Antes de prosseguir na discussão sobre o caráter social e público que desempenham os museus é necessário fazer uma diferenciação entre ensino formal, não-formal e informal. Alencar (2008, p. 19) defende que "a educação formal pode ser considerada como aquela ocorrida nas escolas e instituições de ensino em todos os níveis". A educação não intencional, ou seja, aquela que precede um aprendizado institucionalizado ou certificado, 
que não seja por meio de ensino especificamente, é chamada de educação informal. Já a educação não-formal é também institucionalizada - como a formal - porém é aquela que não acontece na escola, mas em espaços alternativos de ensino e que nesse caso não pode ser certificada.

Por meio da conceituação e significação desta mediação é que se pretende entender a prática educacional dentro do espaço museológico neste texto. Desvelar a real utilização da palavra mediação é conceber que antes de ser assim denominada ela já era prática recorrente e presente em espaços culturais em geral. As modificações de nomenclaturas deste profissional, cabe salientar, estão extremamente ligadas a uma mudança de postura. As responsabilidades e a incumbência do profissional responsável pela educação nos museus, neste caso específico museus de arte, foram sendo transformadas conforme o conteúdo exposto solicitava uma reflexão além daquela obtida através do olhar puro ou da listagem de informações quase catalográficas.

Quando os museus e campos culturais se viram diante da necessidade de ter um membro de sua equipe responsável por receber o público, este profissional era conhecido como guia. Para ser um guia bastava saber e decorar o maior número de informações acerca de determinada obra ou tema. Ele era aquele que 'guiava'; ele passava informações e detalhamentos, conforme Barbosa (2008, p. 31) o termo "visita guiada pressupõe a cegueira do público e a ignorância total".

A partir do momento em que aconteceu uma mudança, ou seja, o profissional não determinava mais tantos limites para o espectador, mas o comandava dentro do espaço, o posto passou a ser do monitor. O monitor era aquele que concedia explicações, aquele que desempenhava a conhecida "educação bancária" de Paulo Freire (1996), o que muitas vezes aniquilava as múltiplas possibilidades de interpretações dos objetos artísticos. Cocchiarale afirma que o público está em uma busca ansiosa pela explicação verbal de obras reais e concretas, como se sem a palavra fosse-nos impossível entendê-las. "A explicação assassina a fruição estética, já que ao reduzir a obra a uma explicação mata sua riqueza polissêmica e ambígua, direcionando-a num sentido unívoco" (2006, p. 14).

Sendo assim, o monitor era o profissional que determinava o percurso da visita, os olhares e as percepções. Este, porém, também é um termo preconceituoso, para Barbosa (2008, p. 30) “(...) monitor é quem ajuda um professor na sala de aula ou é o que veicula a imagem gerada no HD, no caso de computadores. Atrelada à palavra, vai a significação de veículo e de falta de autonomia e de poder próprio". 
Em decorrência de uma ressignificação da arte, o educador de museus precisou desdobrar e alterar sua posição diante do público. Assim surge o mediador supracitado, aquele que relaciona, dialoga, atrai do espectador sua própria contextualização daquela obra de arte. Cocchiarale (2007, p. 15) assegura que "O monitor, o educador, o mediador deve ser menos a pessoa que transmita conteúdos e mais alguém que estimule o público a estabelecer algumas relações de seu próprio modo". Compreende-se que enquanto mediador, o educador é muito mais um propositor do que um depósito de informações e dados a ser despejado. Conforme Martins (2005, p. 17):

O papel de um mediador é importante para a criação de situações onde o encontro com a arte, como objeto de conhecimento, possa ampliar a leitura e a compreensão do mundo e da cultura. Capaz também de abrir diálogos internos, enriquecidos pela socialização dos saberes e das perspectivas pessoais e culturais de cada produtor/fruidor/aprendiz. Pois, o objetivo maior não é propiciar contato para que todos os aprendizes conheçam este ou aquele artista, mas sim que eles possam perceber como o homem e a mulher, em tempos e lugares diferentes, puderam falar de seus sonhos e seus desejos, de sua cultura, de sua realidade, da natureza à sua volta e de suas esperanças e desesperanças, de seu modo singular de pesquisar a materialidade através da linguagem da arte.

A prática da reflexão e de um provocador estético já é bastante presente; ainda que a titulação seja lenta e a palavra monitor continue sendo usada consecutivamente. Por mais que mediação já seja um termo de uso comum, sobretudo no campo específico dos museus e espaços expositivos, ainda é pouco citado pelos teóricos da área que este conceito tenha provido de teorias de desenvolvimento e aprendizagem da psicologia sócio-histórica.

\section{A contribuição de Vygotsky para a educação em museus}

Dentro da perspectiva do desenvolvimento humano, a relação entre os sujeitos e os meios foi amplamente estudada pela psicologia sócio-histórica; cujos conceitos começam com a premissa de que os fenômenos psicológicos são constituídos simultaneamente enquanto os indivíduos interagem socialmente. "Um importante princípio básico da psicologia sócio-histórica é que os seres humanos transformam-se ativamente à medida que transformam seu mundo social e natural" (Ratner, 1995, p. 6).

Diversos teóricos trabalharam dentro desta perspectiva, mas aqui cabe apenas citar aquele que empregou propriamente o verbete pesquisado: Lev S. Vygotsky. Segundo a teoria vygotskiana, toda relação do indivíduo com o mundo é feita através de instrumentos técnicos e da linguagem - que traz consigo conceitos consolidados da cultura à qual 
pertence o sujeito. Segundo Vygotsky (1998, p. 24), "o verdadeiro curso do desenvolvimento do pensamento não vai do individual para o socializado, mas do social para o individual".

Vygotsky encara o processo da aprendizagem como uma ação social onde os indivíduos formulam seus conhecimentos mediante sua interação com o campo e com os outros, numa relação constante entre fatores individuais e coletivos, do sujeito e do contexto. Outros teóricos afirmaram que o social é princípio básico da aprendizagem, tal qual Simon, 1987 apud Passerino; Santarosa (2009, s/p):

(...) a interação social implica na participação ativa dos sujeitos num processo de intercâmbio, ao qual aportam diferentes níveis de experiências e conhecimentos. É claro que nem toda interação social implica numa aprendizagem, existindo categorias de interações das puramente sociais até as didáticas. É através dessas interações de caráter didático, que os sujeitos "aprendem", ou seja se apropriam do conhecimento, não como um objeto, que pode ser avaliado e observado independente do sujeitoobservador, mas conhecimento como uma forma de ser, isto é, conhecimento como ação adequada num contexto determinado.

Esta noção de que não existe a obrigatoriedade na relação ensino-aprendizagem, isto é, que nem toda proposição de ensino se encaminha necessariamente para uma total compreensão dela é bastante contemporânea e autocrítica para a arte-educação e a educação como um todo. Além disso, na citação de Richard Simon compreende-se o porquê do termo mediação exemplificar e delimitar com exatidão a prática educacional que vêm desempenhando as instituições contemporâneas de caráter cultural.

Retomando a noção de conceito de aprendizagem trazida pela psicologia sóciohistórica, cabe colocar que este não é um processo unilateral, conforme salienta Toulmin, 1978 apud Ratner (1995, p. 7):

O fato de a psicologia ser socialmente construída significa que ela não é subproduto direto de mecanismos fisiológicos internos, nem de estímulos físicos externos. Muito pelo contrário, a atividade psicológica socialmente construída medeia o impacto de estímulos internos e externos - de maneira seletiva, ocupando-se deles, interpretando-os, levantando hipóteses sobre eles, fazendo interferências a partir deles, sintetizando-os e analisando-os.

Esta atividade psicológica acima descrita nada mais é do que a relação estabelecida numa ação educativa entre um mediador e o espectador/público em contato com o objeto artístico. É o mediador que se ocupa dos conceitos, interpreta as relações, levanta hipóteses sobre as leituras e faz interferências do repertório pessoal. Sendo assim, percebe-se que a 
categorização do profissional de museu incumbido da educação especificamente como mediador é concreta tanto no sentido epistemológico, quanto no sentido prático da ação.

A teoria colocada pela psicologia sócio-histórica sobrepuja a questão da aprendizagem extremamente relacionada com a linguagem, segundo Vygotsky (1998, p. 7), "a transmissão racional e intencional da experiência e pensamento a outros requer um sistema mediador, cujo protótipo é a fala humana, oriunda da necessidade de intercâmbio entre o trabalho". Este 'sistema mediador' foi transportado para dentro do espaço cultural inicialmente como atributo para transmissão de informações, mas hoje se coloca muito mais como um suscitador de reflexões pessoais.

Para Vygotsky (1998), como mencionado anteriormente, o aprendizado está vinculado a incorporação da fala, visto que o desenvolvimento acontece muito antes da criança iniciar sua vida escolar. A formação de um conceito inicialmente provém da relação entre o som e o significado de uma palavra. Percebe-se então, que a linguagem é a principal mediadora do sujeito com o meio e que cumpre fundamental função no processo de educação, pois sem linguagem não há aprendizagem. É por meio da linguagem que o indivíduo produz cultura; é mediante linguagem que o homem organiza o mundo simbolicamente, criando os museus, por exemplo.

Na busca de uma síntese, a mediação é um processo de intervenção de um elemento numa relação objeto-sujeito, "O uso de signos conduz os seres humanos a uma estrutura específica de comportamento que se destaca do desenvolvimento biológico e cria novas formas de processo psicológicos enraizados na cultura" (Vygotsky, 2007, p. 34).

Sintetizando, segundo Vygotsky, a mediação é uma propriedade da cognição humana, que se refere à assimilação de atividades e comportamentos sociais, históricos e culturais; e, por sua vez, inclui o uso de ferramentas e de signos dentro de um contexto social. A mediação, no caso específico dos espaços expositivos, entre público e objeto de arte, é realizada não apenas pelas ferramentas, bem como pela relação com outros indivíduos que constituem um contexto repleto de outras significações e influenciando o processo de construção do próprio pensamento e da tomada de consciência.

\section{Mediação cultural e museus de arte}

Durante muito tempo a arte exposta nos museus permaneceu inócua e isolada em seu meio, somente atingindo uma escassa elite com conhecimento específico na área. $O$ público que buscava acesso às obras de arte era já iniciado e compreendia o sentido daquela criação; isso por conta dos princípios do colecionismo, quando a arte era fator 
diferencial de poder monetário, separando aqueles que tinham possibilidade de adquirir objetos estéticos dos que nem ao menos viam sentido nas imagens. Também a educação artística limitou-se por um longo período ao ambiente escolar. A afirmação de que a arte produzida na escola não é Arte, ocasionou uma dissonância entre aquilo que era produzido e o que era ensinado.

Com uma postura diferenciada de acessibilidade da arte para todos, a necessidade da arte-educação tornou-se maior que a cisão entre as linhas da poética e do ensino. Essa mudança de postura sucedeu, sobretudo, com a Revolução Francesa, quando houve uma reavaliação da função do museu e estes passaram a ser vistos como uma instituição de acesso e domínio público. Segundo Castellen (2004, p. 18):

Somente a partir da Revolução Francesa, em 1789 é que, o acesso às grandes coleções efetivamente tornou-se públicas. Antes as principais funções dos museus estavam restritas a coletar, conservar e pesquisar. Quando a função expositiva passou a ser predominante, os museus foram obrigados a re-organizarem suas coleções tornando suas exposições em objeto de interesse coletivo.

Pós-Revolução, ao perder-se este caráter excludente e elitista do campo artístico, aconteceu outra mudança, tornando a arte mais informativa e didática aos olhares do público. Segundo Franz (2001, p. 43) "Nessa perspectiva, não bastava apenas permitir a entrada do povo nos museus, assim como eles se apresentavam antes da Revolução Francesa; era preciso mudanças, desde conceituais a estruturais". Em vista da condição neste momento imposta é que as instituições culturais passaram a ter necessidade de um educador em seu corpo de trabalho.

Porém, a criação da função de arte-educador dentro do espaço museológico tardou para acontecer, foi somente no século XIX, em 1852, no Victoria and Albert Museum, como informa Barbosa (1999, p. 84). Desde então, diversos museus têm incorporado a categoria dentro de seu quadro de funcionários, inclusive formando núcleos de arte-educação. "No Novo Mundo é somente no século XX que a função educacional do museu começa a ser colocada no mesmo grau de importância que sua função de preservação e exibição das obras de arte" (BARBOSA, 1999, p. 85).

O histórico temporal das práticas educativas em museus no Brasil provém não de museus de arte, mas de história; e percorre uma trajetória desde a efetivação de ações experimentais isoladas até a iniciativas institucionais. Barbosa $(1999$, p. 83) afirma que o trabalho de arte-educador dentro de museus brasileiros foi improvisada em seu princípio, na 
década de 1950, quando houve uma tentativa de formar os primeiros serviços educativos no Rio de Janeiro.

Já em Florianópolis, segundo Franz (2001, p. 46), as atividades referentes a setores de arte-educação iniciaram-se somente em 1988 com a criação do Setor de Arte-educação do Museu de Arte de Santa Catarina - MASC. Antes disso, porém, a partir da década de 60, com a fundação da Escolinha de Arte também pelo MASC (que nesta época era conhecido como Museu de Arte Moderna de Florianópolis - MAMF), o professor Carlos Humberto desenvolve atividades com crianças dentro do museu, condicionando assim uma iniciativa para a prática de núcleo hoje presente.

Com a delimitação e a organização efetuada dentro das próprias instituições, os órgãos centralizadores de pesquisas passam a definir razões e conceitos. Diante desse fato agora instaurado de que todo museu estrutura um quadro para educador dentro de seu organograma foi necessária a definição de ação educativa, ou seja, o que torna a prática educacional não-formal diferenciada da executada convencionalmente nas escolas. De acordo com a definição do ICOM, a ação educativa compreende os

(...) procedimentos que promovem a educação no museu, tendo o acervo como centro de suas atividades. Pode estar voltada para a transmissão de conhecimento dogmático, resultando em doutrinação e domesticação, ou para a participação, reflexão crítica e transformação da realidade social. Neste caso, deve ser entendida como ação cultural, que consiste no processo de mediação, permitindo ao homem apreender, em um sentido amplo, o bem cultural, com vistas ao desenvolvimento de uma consciência crítica e abrangente da realidade que o cerca. Seus resultados devem assegurar a ampliação das possibilidades de expressão dos indivíduos e grupos nas diferentes esferas da vida social. Concebida dessa maneira, a ação educativa nos museus promove sempre benefício para a sociedade, em última instância, o papel social dos museus.

Concebe-se a ação educativa e cultural como uma política social e de caráter público. Afinal, o objetivo de atuação dos museus hoje em dia é muito mais a postura de agenciador cultural e histórico. Quando se concebe que já é função sacramentada a possibilidade de educar-se através de exposições e mostras é importante se questionar, bem como Júnia Sales Pereira (2007, p. 32) aponta, "O que é e como explorar o que esses espaços oferecem para a aquisição de conhecimentos, para uma educação dos sentidos e do olhar e para a formação de atitudes, diante do outro e dos bens culturais?". Este questionamento desdobra-se em outras perguntas, como: como o mediador pode articular a 
arte com o espectador, trazendo o olhar do outro para a obra? Porque a arte pede um mediador?

É importante enfatizar que se têm dimensão do potencial da obra de arte e se sabe que nem sempre é necessária a figura do mediador para o entendimento desta. Pelo contrário, como supracitado, o mediador não está disponível para conceder informações, mas para provocar. Fica claro que a presença de um educador dentro dos museus apareceu devido à necessidade imposta pela nova função, pelo novo papel dos museus desde a Revolução Francesa. O que ainda não foi evidenciado é que além da necessidade da própria instituição, há a indispensabilidade para com a arte. Esta pede uma interlocução por conta da multiplicidade de interpretações que podem ser alcançadas, conseguidas.

É imprescindível contemporaneamente que o arte-educador esteja presente dentro do espaço cultural e é de grande importância que a escola vá ao museu, porque assim o estudante pode ter contato direto com a obra de arte $^{3}$.

Uma visita a um museu pode levar à ampliação da capacidade de observação, ao entendimento de questões sociais - muitas vezes tratadas pelos artistas, ao enriquecimento do repertório de técnicas, materiais e ações que envolvem a expressividade. $O$ ambiente diferenciado dos museus já é um estímulo à percepção e ao questionamento. (ROSA; SCALÉA, 2006, p. 70)

Habitualmente as aulas de arte se utilizam das imagens da história da arte, porém sempre através de reproduções não fidedignas aos elementos formais das imagens. A presença em grupo dos alunos também favorece a multiplicidade de olhares e interpretações das obras, como reforça Martins (2005, p. 17):

A mediação se enriquece na troca de pontos de vista de cada um no seu grupo, acrescidos de outros trazidos por teóricos e estudiosos, que podemos apresentar, rompendo com preconceitos estereotipados, ampliando conhecimentos e partindo para novas problematizações. A socialização destes pontos de vista é, portanto, imprescindível para a ampliação de compreensão da arte, ultrapassando o perigo de colocar na voz do mediador (monitor, professor ou teórico) a interpretação que poderia ser colocada como única e correta.

\footnotetext{
${ }^{3}$ Mesmo sabendo que a formação de professores de artes não é objeto de estudo deste texto acreditamos que a ida dos estudantes ao museu adiciona elementos de atualização também na prática do professor de arte.
} 
O mediador posiciona-se como um contextualizador, ele promove o encontro entre o repertório que o próprio público possui com as referências imagéticas e teóricas que ele possui acerca do artista, da obra, do tema, do enredo, dos aspectos formais etc. O encontro provocado pela visita de alunos de ensino formal possibilita a condição de um olhar diferenciado para a obra de arte. Martins (2005, p. 44) afirma que "A mediação pode ser compreendida como um encontro, mas, não como qualquer encontro. Um encontro sensível, atento ao outro". A atenção ao outro provém, sobretudo do educador, mas sucede consecutiva e consequentemente com o grupo; e este encontro sensível é coletivo e de cooperação.

A noção de trabalho coletivo e de cooperação aparece como indispensável também no trabalho realizado para a promoção dos eventos dentro dos museus. Por muito tempo os setores de arte-educação permaneceram como apêndices colocados na estrutura da gestão de museus (isso inclusive ocorre até os dias de hoje). Iniciativas de educadores administrando museus de grande porte trouxeram uma nova dimensão para núcleos educativos de muitas instituições - como o caso do Museu de Arte Contemporânea da USP que foi gerido por Ana Mae Barbosa, como também do Museu de Arte Contemporânea de Niterói, administrado durante muitos anos por Luiz Guilherme Vergara.

É preciso aceitar que é necessária uma cooperação entre o trabalho realizado pelo arte-educador e o trabalho do curador. Essa relação foi colocada por Barbosa (1999, p. 87) quando estabeleceu que uma das missões do MAC-USP era "interrelacionar curadoria, pesquisa e arte-educação, sem modelo fixo, a partir da premissa de que tanto o curador quando o arte-educador têm a responsabilidade de facilitar a comunicação e a apreciação do público". Esta não é ainda prática habitualmente recorrente, como afirma Barbosa (1999, p. 84), "na maioria dos museus o arte-educador é um apêndice e é até dirigido, orientado, pelo curador, que diz o que deve ser feito ou como deve ser lida a exposição pelo público e compete ao arte-educador apenas orientar para aquela leitura ou executar a animação proposta".

Uma mudança de postura da instituição como promotora desta parceria mediadorcurador aparece com a criação de um novo termo: a Curadoria Educativa. Este termo apareceu com força na $6^{a}$ Bienal do Mercosul, em Porto Alegre no ano de 2007, porém foi criticado por Ana Mae Barbosa (2008, p. 32): "Curadoria educativa não é propriamente preconceituoso, mas é usado para dissimular preconceito. É só um meio artificial de tentar conferir a mesma importância da educação à curadoria de obras de arte". 
Aproximadamente dez anos antes, Barbosa (1999, p. 84) já tinha afirmado que os papéis do educador e do curador são associados para promover a participação, visitação e entendimento do público:

Ao arte-educador compete ajudar o público a encontrar seu caminho interpretativo e não impor a intenção do curador, da mesma maneira que a atitude de adivinhar a intencionalidade do artista foi derrogada pela priorização da leitura do objeto estético por ele produzido. As atividades da arte-educação e do curador são complementares: interpretar uma exposição é tão importante quanto instalá-la! São atividades que têm como suporte teorias estéticas, conceituação de espaço e de tempo.

Se a produção artística a ser exposta fosse dialogada e conversada entre educadores e curadores haveria uma maior coerência no discurso apresentado para os maiores interessados no assunto: o público. Por vezes, a falta de diálogo entre a produção da exposição - o antes - e a organização da ação educativa - o depois - é tão grande que o público passa a não compreender o sentido daquela mostra. A incompreensão é ainda maior quando se trata de arte contemporânea.

A resistência à arte contemporânea ainda persiste e prejudica a ação mediadora, visto que o público se mostra incisivamente contra a produção do pós-modernismo. O que prepondera é a relação que Cocchiarale (2006) estabelece de que concebemos melhor aquilo que já há mais tempo foi registrado artístico-historicamente. O que esta resistência provoca é uma retaliação e uma incompreensão de que a arte contemporânea é muito mais próxima do público do que este pode notar. É na arte contemporânea que está a maior riqueza de aberturas e desdobramentos que o mediador pode provocar no pensamento coletivo e individual do grupo, conforme Bemvenuti (2004, p. 19):

O jogo de olhares, de questionamento, de reflexões que a arte contemporânea propõe é tão próximo de nossas necessidades cotidianas, que muitas vezes não acreditamos ser o que vemos, pois exigimos, através de nossa reação, estar diante de monalisas e santas ceias, onde os códigos de linguagem são nossos conhecidos, mesmo que não tenhamos domínio sobre a narrativa e temas apresentados. É possível estabelecer uma comparação, uma aproximação entre as posturas do ser contemporâneo frente à obra de arte.

Ser contemporâneo frente à obra de arte é o papel do mediador; afinal, podem ser compreendidos como sinônimos para a ação de mediar: "provocar, ampliar, despertar, trocar, instigar, motivar/estimular, facilitar/favorecer, enriquecer, desenvolver, criar, passar, 
orientar, diagnosticar, conduzir/levar, apoiar, efetivar, auxiliar, mostrar, objetivar, suprir, conduzir, articular, incorporar, informar" (MARTINS, 2005, p. 43).

Todo professor de artes faz uso destes verbos sinônimos de mediar, seja ele do ensino formal ou não-formal. O professor de sala de aula é participante também do processo da visitação à exposição; há um intercâmbio entre museu, professor e escola. Conforme Pereira (2007, p. 36) "O professor é sujeito do processo educativo, aprende com as oportunidades formativas que vivencia e está aberto ao diálogo proporcionado pela equipe do museu e pelos alunos. Como instituição formadora, o museu também se institui no lugar da promoção do trabalho compartilhado e do diálogo".

O professor é sujeito reflexivo que em sua produção teorico-prática atua como propositor, tal qual afirmou Lygia Clark (1983, s/p): "Nós somos os propositores: nós somos o molde. Nós somos os propositores: nossa proposição é o diálogo. Sós, não existimos". Vigorando o diálogo com alunos, com o sistema escolar, com a Arte como campo de conhecimento e com os espaços culturais, o professor torna-se sujeito propositor de suas ações e reflexivo de seu processo, concomitantemente.

Para as ações educativas realizadas em espaços expositivos não é diferente. O mediador atua como propositor e o exercício teórico é pertinente e ponto de partida para toda e qualquer mediação. O mais apaixonante deste campo é que a pesquisa é habitualmente prática de grupo e, portanto de interlocução. As parcerias firmadas para a realização de uma ação educativa são diárias e permanentes.

Os estudantes, tais quais os professores, devem ser seduzidos pelos museus. Eles devem sentir a aproximação que a arte tem com a vida e com o repertório de imagens que eles possuem. Pois se o ensino de arte está presente nas escolas para provocar uma visão crítica da imagem de maneira geral, os museus e centros culturais são os ambientes de aproximação desta nova realidade crítica que o ensino de arte colocará.

Sem acesso a equipamentos culturais a população pode não desenvolver hábitos, valores, atitudes na relação com a cultura, nem é capaz de construir o olhar crítico sobre as produções artísticas visuais e outras, como outdoors, cinema, propagandas, revistas em quadrinhos, grafite, televisão, etc. Identificar e discutir arte fora da sala de aula é fundamental para a compreensão de que a arte pode estar relacionada com a vida. (ARSLAN; IAVELBERG, 2006, p. 41)

A aproximação da arte com a vida é questão relevante e recorrente nas artes visuais. O museu pode atuar como um espaço de reflexão crítica. A possibilidade de dentro do 
museu nós conseguirmos articular pensamentos, enriquecer repertórios e objetivar olhares torna estes espaços extremamente pedagógicos; e isso independe da atuação de um educador. A visitação pode provocar o exercício crítico na leitura de textos, distribuição de folders e na disposição expográfica dos objetos.

É possível, como afirma Robert Ott (1999, p. 113), ensinar crítica nos museus. Esta aproximação proporciona a descoberta de que a arte é conhecimento e sendo assim "(...) proporciona meios para a compreensão do pensamento e das expressões de uma cultura". A crítica de arte exercitada no interior no museu, frente à obra de arte original, leva o visitante a compreender a arte como meio de comunicação da sociedade contemporânea.

Compreender a arte criticamente é o subterfúgio mais conveniente para encontrar-se com a arte. Esta arte encontra-se habitualmente nos museus e por isso estes são os espaços mais comuns de aproximação com os objetos artísticos. Ainda que conforme Bourdieu (2007) o público cativo de frequentar os museus tenha um perfil específico, cabe aos setores educacionais destas instituições promover o encontro deste com a arte; e ela por si atingirá cada espectador de alguma maneira.

É dever do poder público favorecer o contato com a arte e deve ser um papel desempenhado pelos órgãos ligados a cultura promover a ida aos espaços expositivos. encontro com a arte é o mais evidente fator benéfico que os museus, galerias e centros culturais podem apresentar para o público. Os objetos artísticos estão acessíveis e as formas de compreensão podem ser as mais diversas. O museu deve ser um espaço de encontro permanente e também desencadeador de processos. E este acesso fornecido para o público em geral é, definitivamente, mais utilizado pelo público escolar.

A formação básica e escolar pode muitas vezes subsidiar a necessidade de compreender criticamente as imagens que nos rodeiam, porém cabe aos mediadores também atuarem como formadores de público. Ao enriquecer o repertório visual do público, os educadores em geral e principalmente os educadores de museus estão atuando para engrandecer suas ações e ampliar a gama de espectadores que acompanham este trabalho.

A aproximação do público em relação à arte estabelece-se como o cumprimento de um dos objetivos que os setores educativos dos museus e centros culturais devem desempenhar: que é a função de formadores de público. Os setores educativos são os maiores agenciadores de visitas aos museus e o é o maior multiplicador de público que a instituição pode ter como parceiro. 
O mediador, por sua vez, deve portar-se como um interlocutor que torne a ação educativa uma prática de ensino de arte coletiva. Pois tal qual afirma Vygotsky (1998) a efetiva aprendizagem procede do coletivo para o individual. Sendo assim, cabe ao mediador portar-se como o agenciador dos repertórios coletivos e torná-los concepções críticas e individuais.

O caráter social de formação de público é evidenciado e atingido com a efetivação de programas educativos. Eles são a frente de trabalho do museu em relação aos seus visitantes e é o educador quem dialoga e estabelece ligações com o público. O mediador fica no meio, mas sem ser ponte ou acesso, ele mostra os caminhos e apresenta a rede de relações que podem ser coletiva e socialmente construídas.

Referências:

ALMANDRADE. 0 museu e sua função cultural. Disponível em:< http://www.forumpermanente.org/.painel/artigos/almandrade/> . Acesso em: 11 mar. 2009.

ALENCAR, Valéria Peixoto de. O mediador cultural - Considerações sobre a formação e profissionalização de educadores de museus e exposições de arte. 2008. Dissertação (Mestrado em Artes) Universidade Estadual Paulista, Instituto de Artes, São Paulo, 2008.

ARSLAN, Luciana Mourão; IAVELBERG, Rosa. Ensino de arte. São Paulo: Thomson Learning, 2006.

BARBOSA, Ana Mae. A imagem no ensino da arte. São Paulo: Editora Perspectiva, 1999. Educação em Museus: termos que revelam preconceito. In: AQUINO, André (org.). Diálogos entre arte e público - Caderno de textos. Recife/PE: Fundação de Cultura da Cidade de Recife, 2008.

Tópicos utópicos. Belo Horizonte: C/ Arte, 1998.

BEMVENUTI, Alice. Museus e educação em museus: história, metodologias e projetos. Com análises de caso: museus de arte contemporânea de São Paulo, Niterói e Rio Grande do Sul. In: MEDEIROS, Maria Beatriz de (org.). Arte em pesquisa: especificidades. Brasília/DF: Editora da Pós-graduação em Arte da Universidade de Brasília, 2004, v.2. 
BOURDIEU, Pierre. O poder simbólico. Lisboa: Difel, 1989.

BOURDIEU, Pierre; DARBEL, Alain. O amor pela arte - Os museus de arte na Europa e seu público. Porto Alegre/RS: Zouk, 2007.

CASTELLEN, Christiane Maria. Museu de Arte de Santa Catarina e suas ações educativas como possibilidades de inclusão social através de parcerias. 2004. Dissertação (Pós-graduação Lato Sensu em Ensino de Artes Visuais) - Universidade do Estado de Santa Catarina, Florianópolis, 2004.

CLARK, Lygia. Livro-obra. Rio de Janeiro, 1983.

COCCHIARALE, Fernando. Quem tem medo da Arte Contemporânea? Recife: Fundação Joaquim Nabuco, Editora Massangana, 2006.

EFLAND, Arthur D. Cultura, sociedade arte e educação num mundo pós-moderno. In: BARBOSA, Ana Mae; GUINSBURG, J. (orgs.). O pós-modernismo. São Paulo: Perspectiva, 2005.

FRANZ, Teresinha Sueli. Educação para a compreensão da arte - Museu Victor Meirelles. Florianópolis: Insular, 2001.

FREIRE, Paulo. Pedagogia da autonomia: Saberes necessários à prática educativa. São Paulo: Paz e terra, 1996.

ICOM - International Council of Museums. Museum definition - 1974. In: Development of the museum definition according to ICOM Statutes (1946 - 2001). Disponível em:< http://icom.museum/hist def eng.html>. Acesso em: 12 mar. 2009.

LEWIS, Geofrey. O papel dos museus e o código de ética profissional. In: BOYLAN, Patrick J. Como gerir um museu: Manual prático. Paris: ICOM, 2004.

MARTINS, Mirian Celeste. Mediação: provocações estéticas. Universidade Estadual Paulista - Instituto de Artes. Pós-graduação. São Paulo, v. 1, n. 1, 2005.

NASCIMENTO, Júnior José do; CHAGAS, Mário de Souza. Diversidade museal e movimentos sociais. In: NASCIMENTO Júnior, José do (org.). IBERMUSEUS 2: Reflexões e comunicações. Brasília/DF: Instituto do Patrimônio Histórico e Artístico Nacional, Departamento de Museus e Centros Culturais, 2008a. 
NASCIMENTO, Júnior José do; CHAGAS, Mário de Souza. Panorama dos museus no Brasil. In: NASCIMENTO Júnior, José do (org.). IBERMUSEUS 1: Panoramas museológicos da Ibero-américa. Brasília/DF: Instituto do Patrimônio Histórico e Artístico Nacional, Departamento de Museus e Centros Culturais, 2008b.

O'DOHERTY, Brian. No interior do cubo branco: a ideologia do espaço da arte. São Paulo: Martins Fontes, 2002.

OTT, Robert William. Ensinando crítica nos museus. In: BARBOSA, Ana Mae (org.). Arteeducação: leitura no subsolo. São Paulo: Cortez, 1999.

PASSERINO, Liliana Maria; SANTAROSA, Lucila Maria Costi. Uma visão sócio-histórica da interação dentro de ambientes computacionais. Disponível em:< http://lsm.dei.uc.pt/ribie/docfiles/txt200372911757Uma\%20vis\%C3\%A30\%20s\%C3\%B3ciohist\%C3\%B3rica.pdf>. Acesso em: 24 mar. 2009.

PEREIRA, Júnia Pereira. Escola e museu - Diálogos e práticas. Belo Horizonte: Secretaria de Estado da Cultura - Superintendência de Museus / Cefor, 2007.

ROSA, Nereide Schilaro Santa; SCALÉA, Neusa Schilaro. Arte-educação para professores - Teorias e práticas na visitação escolar. Rio de Janeiro: Pinakotheke, 2006.

THISTLEWOOD, David. Estudos críticos: O museu de arte contemporânea e a relevância social. In: BARBOSA, Ana Mae (org.). Arte-educação: leitura no subsolo. São Paulo: Cortez, 1999.

VYGOTSKY, Lev S. A formação social da mente - O desenvolvimento dos processos psicológicos superiores. São Paulo: Martins Fontes, 2007.

Pensamento e Linguagem. São Paulo: Martins Fontes, 1998. 